\title{
ANÁLISE DA FORMAÇÃO DO ENFERMEIRO PARA A ASSISTÊNCIA DE ENFERMAGEM NO DOMICÍLIO
}

\author{
Emília Luigia Saporiti Angerami* \\ Daisy Leslie Steagall-Gomes*
}

\begin{abstract}
ANGERAMI, E.L.S.; GOMES, D.L.S. Análise da formação do enfermeiro para a assistência de enfermagem no domicílio. Rev. latino-am. enfermagem, Ribeirão Preto, v. 4, n. 2, p. 5-22, julho 1996.
\end{abstract}

A observação de que há um retorno à assistência domiciliária levou os autores a realizarem este estudo com o objetivo de analisar a formação do enfermeiro para este cuidado. Foram demarcados quatro períodos históricos nos quais estão identificados alguns fatos que direta ou indiretamente influenciaram a enfermagem brasileira e a formação dos profissionais. Os autores procuraram nos currículos mínimos fixados a partir de 1923, as disciplinas de saúde pública e nelas os conteúdos que favorecem a formação para a prática dessa assistência. A descrição de dois serviços (público e privado) que utilizam esta assistência subsidia a discussão de que efetivamente há uma tendência para este tipo de cuidado e que a formação do enfermeiro tradicionalmente não contemplou nem contempla este preparo, constituindo-se, frente à realidade e à expansão do mercado, em uma área relevante.

UNITERMOS: enfermagem no domicílio, formação, currículo

No fim do século passado e início deste, o paciente era assistido no seu domicílio pelo médico de família e por uma enfermeira contratada para prestar cuidados.

As transformações ocorridas na assistência médica ao longo deste século, com a crescente hospitalização dos doentes, provocaram mudanças que repercutiram na formação de enfermeiras e no mercado de trabalho.

\footnotetext{
* Docentes da Escola de Enfermagem de Ribeirão Preto da Universidade de São Paulo - Brasil e Pesquisadores do Grupo de Investigação em Recursos Humanos em Enfermagem da mesma Escola. Projeto CNPq
}

Rev. Latino Am. Enf. - Ribeirão Preto - v. 4 - n. 2 - p. 5-22 - julho 1996 
A observação de que há um movimento de retorno ao cuidado do paciente em sua casa, determinado por fatores econômicos, sociais e emocionais, levounos à realização deste estudo que tem como objetivo analisar a formação do enfermeiro para o cuidado no domicílio.

Os conhecimentos e habilidades necessários para o atendimento do cliente em sua casa são tradicionalmente desenvolvidos nas práticas de Saúde Pública. Assim sendo, os autores procuraram, nos diferentes currículos mínimos fixados, as disciplinas de Saúde Pública e nelas os conteúdos que favorecem a formação para a prática da assistência domiciliar.

Fatos históricos relevantes para a enfermagem conformaram o trabalho em quatro períodos, nos quais se procurou estabelecer relações entre a formação do enfermeiro e as transformações em processo nos Sistemas de Saúde e Educacional.

Assim, nos períodos históricos demarcados estão descritos os fatos que direta ou indiretamente influenciaram a enfermagem brasileira e a formação profissional.

O primeiro mostra as raízes da enfermagem brasileira ao resgatar a influência da Enfermagem Norte Americana na implantação da primeira Escola de Enfermagem no Brasil, em 1923. O segundo, de 1923 a 1970, descreve o desenvolvimento da: Enfermagem em Saúde Pública, com ênfase em programas de enfermagem nas Universidades, as transformações curriculares e as drásticas mudanças no Sistema de Saúde. O quarto período enfoca a atualidade. As Escolas de Enfermagem preparam-se para implantar, em 1996, uma nova estrutura curricular. O Sistema de Saúde procura redefinir as práticas sanitárias a fim de adequá-las às necessidades da população. As propostas de implantação de programas de assistência no domicílio constituem-se em mais uma estratégia para melhoria do atendimento em saúde. O relato de experiências em desenvolvimento de programas de assistência no domicílio, feito por duas enfermeiras, uma responsável por um programa governamental e outro particular, ilustram a situação atual e permite discutir as tendências desta modalidade de atendimento, o que é feito nas considerações finais.

\section{$1^{\circ}$ PERÍODO: Nas raízes da história}

Nos Estados Unidos, para BEATRICE \& KALISCH (1975) houve, a partir de 1860 e até 1920, um crescente aumento da hospitalização. Para os grupos interessados nestas mudanças, a minimização dos custos e a maximização dos serviços era uma meta a ser conquistada.

O preparo de enfermeiras, profissão predominante para o sexo feminino, passou a ser considerado essencial para o fortalecimento destas metas. Houve, assim, uma explosão de Escolas de Enfermagem e as alunas oriundas das classes 
sociais mais baixas eram submetidas a treinamento hospitalar e rígido controle disciplinar.

Estas estudantes representantes, até 1920, a força de trabalho dos hospitais americanos, impedindo a contratação dos profissionais que recebiam seu diploma, pois as estudantes supriam a baixo custo o trabalho no hospital.

Segundo os autores citados, as estudantes trabalhavam dia e noites, domingos e feriados e eram consideradas propriedades do hospital. As condições de saúde destas alunas eram precárias e eram exigidas submissão, lealdade e religiosidade. $O$ trabalho nas enfermarias era de 8 a 15 horas por dia, durante 6 dias e meio por semana, e recebiam de 2 a 3 horas semanais de aula, o que correspondia ao preparo teórico, ainda considerado excessivo pelos médicos.

Ao terminar o curso de enfermagem, a enfermeira estava apta a se casar ou trabalhar como enfermeira no domicílio, uma vez que o trabalho no hospital era exercido por alunas. Tornou-se, assim, inevitável um ciclo vicioso de desemprego criado pelo aumento do número de profissionais e a diminuição de pacientes, sendo tratados agora em casa (BAER, 1984).

As enfermeiras que trabalhavam no domicílio passaram, por sua independência, a perturbar o sistema hospitalar. Em algumas situações o paciente, ao ser internado, levava sua enfermeira, recebendo dela os cuidados especiais (HEALTH POLICY ADVISORY CENTER, 1975).

Neste contexto, WAGNER (1980) considerou que até 1930, de 70 a $75 \%$ das enfermeiras exerciam atividades independentes e apenas 4000 eram assalariadas de hospitais.

Em 1923. o famoso Goldmark Report tratou do problema da reorientação da prática profissional, com o fim de atingir novos objetivos sociais e de saúde, tendo apresentado recomendações específicas para o ensino, de acordo com esta reorientação. Entretanto, suas conclusões foram lentamente absorvidas, tanto pelos hospitais como pelas enfermeiras particulares, pois as condições de trabalho nos hospitais eram péssimas e o serviço no domicílio pás as enfermeiras ainda oferecia liberdade de escolha do cliente e das horas de trabalho. Este quadro foi modificado pela pressão econômica americana, acabando lentamente com a enfermagem particular, à medida que o desemprego reduziu o poder aquisitivo da clientela.

O grande desemprego de enfermeiras, segundo WAGNER (1980) levou a American Nursing Association (ANA) a desenvolver estratégias para a recuperação da profissão. Basicamente estas ações foram: reduzir o número de Escolas; adequar a oferta ao mercado; estipular 8 horas de trabalho diário; terminar com o uso de estudantes como mão de obra; implantar currículos mínimos.

As enfermeiras independentes lutaram para manter seu status. Entretanto, para o mesmo autor a convenção da ANA, de 1946, marcou o declínio da liberdade de escolher casos, de trabalhar independentemente, propiciar cuidados de cabeceira complexos e manter relacionamentos profissionais com médicos e administradores. 
Havia terminado para a maioria das enfermeiras a independência, tomando-as uma massa de assalariadas dos hospitais em franco desenvolvimento.

A elaboração, em 1917, do Standard Curriculum for Nursing Schools (1954) determinava o tipo de formação para o profissional que deveria atuar no mundo de transformações resultantes da ia Guerra Mundial e do Sistema de Saúde com crescente hospitalização e especialização, além do acelerado avanço da tecnologia.

No Brasil, a situação política e de saúde apresentava características distintas das descritas para os Estados Unidos, entretanto, o relato histórico feito é fundamental para entender-se a implantação da Enfermagem Moderna no país, cujas raízes são norte-americanas.

A enfermagem moderna se desenvolveu num amplo movimento de saúde pública, principalmente voltado para a questão do saneamento dos portos e núcleos urbanos, que mereceram atenção especial e imediata por parte do governo brasileiro, porquanto eram constantes as advertências dos países que comercializavam com o Brasil, de parar as negociações, caso persistissem as constantes epidemias e endemias. Nesse contexto, criou-se o Departamento Nacional de Saúde Pública.

Carlos Chagas, conhecendo o trabalho sanitário que era desenvolvido por enfermeiras nos Estados Unidos, convenceu o governo brasileiro a criar a Escola de Enfermagem Anna Nery no Rio de Janeiro, em 1923, que segundo PULLEN (1940), tinha os preceitos das melhores escolas dos Estados Unidos naquele momento.

PARSON (1927), ao resgatar a história da fundação desta Escola, refere uma grande pressão para colocar enfermeiras no campo da Saúde Pública o mais rápido possível, reduzindo o seu tempo do preparo 2 anos e 4 meses de ensino teórico e prático. Para formação destas enfermeiras sugeriu um preparo complementar em Saúde Pública de, no mínimo, 4 meses. Além disto, as pressões políticas eram tantas que em 6 meses foram preparadas, num curso de emergência, visitadoras sanitárias para mulheres que já estavam no emprego - curso que durou até 1926 - quando as visitadoras foram substituídas por enfermeiras já preparadas para atividades de Saúde Pública. Estas primeiras graduadas receberam o título de Enfermeiras de Saúde Pública e passaram a atuar no Departamento Nacional de Saúde Pública (ALCÂNTARA, 1963).

O primeiro Currículo Mínimo implantado no Brasil, segundo CARVALHO (1972), mostra uma grande semelhança com o Standard Currículo de 1917, tanto na parte teórica como prática.

Detecta-se neste currículo a existência de conteúdos relacionados à higiene, saúde pública, doenças venéreas e da pele, e o desenvolvimento da prática predominantemente nos hospitais. Este pode ser o motivo que levou PARSON (1927) a sugerir para a enfermeira de Saúde Pública uma formação complementar, visando suprir as lacunas na sua formação. O desempenho da prática profissional 
exigia preparo para atendimento à comunidade e o currículo privilegiava o cuidado ao indivíduo e ao paciente hospitalizado, mostrando um descompasso entre os órgãos formadores e as necessidades do mercado de trabalho.

\section{$2{ }^{\circ}$ PERÍODO: Um País se transformando - 1923-1970}

Como já foi visto, o saneamento dos portos e o surgimento dos núcleos urbanos como Rio de Janeiro, São Paulo e Santos, parte do sistema exportador e do capitalismo emergente, necessitavam da criação de mínimas condições sanitárias para a viabilização das relações comerciais com o exterior (BRAGA, 1978).

Foram as enfermeiras Ana Neri no Rio de Janeiro que participaram dos programas de combate às endemias, cuidando do isolamento dos pacientes e acompanhando seus contatos. Havia ainda o atendimento domiciliário feito doentes particulares.

Até o final da década de 30 , o mercado de trabalho da enfermeira estava exclusivamente direcionado para a Saúde Pública, tendo sido ampliados diversos serviços nacionais ligados às grandes endemias, especialmente as que atingiam a população rural. As décadas de 40 e 50 caracterizavam-se por um processo acelerado da industrialização e urbanização, exigindo expansão do atendimento à Saúde, mecanismos de inovação dos hospitais e expansão da rede previdenciária. Nesse período, criam-se também os hospitais universitários. Essas transformações na sociedade provocam mudanças no trabalho da enfermeira que, segundo ALCÂNTARA (1963), direcionava-se para administração dos serviços hospitalares, criando um impacto nos serviços de saúde pública, relegados agora a segundo plano.

As transformações que ocorriam no Sistema de Saúde criaram a necessidade de recursos humanos preparados para assumirem as novas funções que se concedendo bolsas de estudo para o preparo de pessoal médico e de enfermagem, no Canadá e Estados Unidos. Seis educadoras sanitárias, em 1938, seguiram para esses Países preparando-se para, no seu retomo, assumirem no Brasil prioritariamente a direção de escolas em expansão.

Este novo papel, associado à administração de serviços, acentuou o interesse pelo preparo em administração de enfermagem e a consciência de que a enfermeira teria que assumir cargos de chefia. Segundo OLIVEIRA (1979), Essa situação motivou a admissão de enfermeiras Ana Neri para organizar o serviço de enfermagem em hospitais, especialmente nos Universitários.

O hospital passava a requerer um envolvimento cada vez maior desse profissional em atividades administrativas, sendo o cuidado direto ao paciente cada vez mais entregue ao pessoal auxiliar.

O aparecimento do Serviço Especial de Saúde (SESP) em 1942 veio 
aumentar o mercado de trabalho para a enfermeira de saúde pública. Iniciou-se assim a penetração da enfermagem em áreas rurais, num trabalho voltado ao controle das epidemias e atenção materno-infantil, logo ampliado para o cuidado do doente nas unidades mistas de internação. Esta instituição teve um papel importante na política sanitária brasileira (BRAGA, 1978).

A área do ensino de enfermagem, em 1942, teve um impulso importante com a criação da Escola de Enfermagem da USP** e o surgimento de hospitais públicos com fins educacionais como o Hospital das Clínicas de São Paulo e o Hospital São Paulo (ALCÂNTARA, 1963).

Outro fato importante foi a promulgação, em 1949 , da Lei $775^{\star \star *}$ que regulamentava o ensino de enfermagem. Esta lei estabelecia a duração de 4 anos para o curso e os candidatos deveriam ter certificado do curso colegial, com tolerância de 12 anos para matrícula de candidatos com o $1^{\circ}$ ciclo do primeiro grau completo.

O conteúdo teórico desse currículo foi ampliado para 29 disciplinas, algumas das quais subdivididas em duas, três ou mais. Incluía estágios obrigatórios, mas sem determinação do número de horas. Esse currículo era uma adaptação do previsto pelo Curriculum Guide de 1937 com maiores exigências (CARVALHO, 1972). Na relação das disciplinas observa-se que a formação em Saúde Pública mantinha as disciplinas do currículo anterior, acrescido do estágio em Serviços Urbanos e Rurais de Saúde Pública, não havendo especificação do tempo em horas.

Mesmo com a introdução desses estágios, Aluin \& Paim (1958) apud BARREIRA E CASTRO (1977) consideram a saúde pública a área mais deficiente da enfermagem, quer em quantidade como em qualidade.

Em relação à enfermagem no domicílio, função tradicionalmente desenvolvida pelas enfermeiras de saúde pública, March (1947) apud BARREIRA E CASTRO (1977) diz que embora continuasse a ser ensinada pelas Escolas de Enfermagem, ela desaparece na prática devido ao declínio da saúde pública.

Entretanto, alguns movimentos tentavam manter o atendimento deste serviço no domicílio, como a criação na década de 50 do Serviço de Assistência Médica Domiciliar e de Urgência - SAMDU, (BRAGA, 1978) e a preocupação da Escola de Enfermagem de Ribeirão Preto (USP) em desenvolver programas educativos na comunidade visando ao atendimento domiciliário, através de cursos de Enfermagem do Lar (MINZONI et al., 1963).

O ensino de enfermagem teve, nas décadas de 40 e 50, uma expansão, atendendo ao aumento da demanda desses profissionais ocorrida principalmente pelo ritmo da urbanização existente e pelo processo de modernização dos hospitais (SILVA, 1984). No final da década de 50, havia em todo país 39 escolas de

\footnotetext{
** Decreto Lei 13.040 de 30 de dezembro de 1942

*** Lei 775 de agosto de 1949. Decreto 27.426 de dezembro de 1949
} 
enfermagem e 67 cursos de auxiliares de enfermagem (REZENDE, 1961). Este crescimento gerou a necessidade de disciplinamento do exercício profissional, o que ocorreu com a promulgação da Lei 2604/55****.

Na década de 60, segundo BRAGA (1978), observa-se ao lado do declínio relativo do subsetor da saúde pública o crescimento do subsetor da medicina previdenciária que já vinha se ampliando desde o final dos anos 50.

Em agosto de 1962, ocorreram mudanças fundamentais no curso de formação

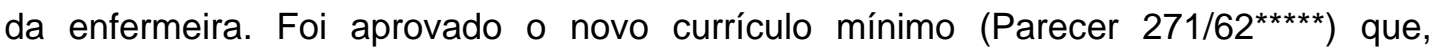
segundo CARVALHO (1972), pela sua simplicidade dava ensejo ao planejamento do ensino visando à integração de conteúdo de diversas disciplinas, incluindo Fundamentação clínica e os aspectos de Saúde Pública. A ausência de matérias dos campos das Ciências Biológicas e Psico-Sociais e de Saúde Pública não significavam sua inexistência.

O curso passou a ser de 3 anos e um $4^{\circ}$ ano optativo em Enfermagem em Saúde Pública, Enfermagem Obstétrica e Enfermagem Médico-Cinirgica.

A Reforma Universitária implantada no País na década de 70 provocou a revisão de todos os currículos para se adequarem ao novo modelo de ensino universitário, o que trataremos a seguir.

\section{PERÍODO: 1970 a 1990 - Uma profissão firmando seu espaço}

Como conseqüência da Reforma Universitária, todos os currículos mínimos dos cursos superiores foram revistos. $O$ de enfermagem foi modificado pelo Parecer $n .^{\circ}$

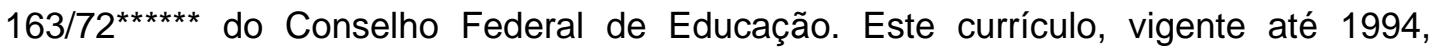
caracterizou-se por ter:

1) Tronco pré-profissional onde o aluno recebia ensinamentos de Ciências Biológicas, Ciências Sociais e Introdução à Saúde Pública.

2) Tronco Profissional.

3) Habilitação em: Enfermagem Médico-Cirúrgico, Enfermagem Obstétrica ou obstetriz e Enfermagem de Saúde Pública, prevendo ainda a Licenciatura em Enfermagem.

O currículo foi bastante criticado, principalmente por propiciar a especialização precoce e aos alunos que não faziam a Habilitação em Enfermagem em Saúde Pública serem oferecidas apenas noções introdutórias dessa disciplina ministrada no curso préprofissional.

\footnotetext{
**** Lei 2604 de 17/09/1955 regula o exercício da enfermagem profissional - D.O. de 12/ 09/1955

**** Parecer 271, aprovado em 19.10.1962 - Currículo Mínimo do Curso de Enfermagem - Documento n. 10 de dezembro de 1962

***** Projeto de Resolução anexa ao Parecer 163, C.C.R. de currículos aprovados em 27/01/1972 Currículo Mínimo dos Cursos de Enfermagem e Obstetrícia. Documenta n. ํ 135, de fevereiro de 1972
} 
Percebe-se que, em decorrência da queda da hegemonia do modelo sanitarista, o ensino de Saúde Pública passou a não ser oferecido para todos os alunos e que a disciplina Administração Geral, neste novo currículo, ganhou ênfase nas habilitações dentro de anos específicos.

Se esta era a tônica da formação profissional, surgia internacionalmente uma nova proposta em saúde com a Declaração de Alma Ata enfatizando os cuidados primários de saúde (ALMA-ATA, 1978).

O ano de 1980 foi marcado pela presença de um dos mais importantes projetos da área da saúde do Brasil, o PREV-SAÚDE, que criava condição para colocar à disposição da população no âmbito nacional, uma rede de serviços de saúde integralizado, regionalizado, hierarquizado e dispondo do sistema de referência que permitiria o atendimento da demanda, nos diversos níveis dos serviços, escalonados de conformidade com a complexidade requerida (COFEN/ ABEn, 1985). No entanto, este Projeto não chegou a ser concretizado na prática, principalmente por pressões políticas.

Em decorrência dos problemas no Sistema de Atenção à Saúde criou-se, em 1982, o Conselho Consultivo da Administração de Saúde Previdenciária (CONASP ${ }^{\star \star \star \star \star \star \star)}$ que elaborou o Plano de Reorientação da Assistência à Saúde no âmbito da Previdência Social, onde se deu prioridade, entre outras, às ações primárias e à integração de serviços mantidos pelos Governos Federal, Estadual e Municipal objetivando a globalização do setor Saúde. Enquanto se discutia esta matéria, articulações e medidas eram tomadas visando a municipalização das ações de saúde.

Nesse mesmo ano já se iniciava a elaboração da nova estrutura organizacional do Sistema Nacional de Saúde que, posteriormente, foi encaminhada e incorporada à Constituição Brasileira promulgada em 5 de outubro de 1988 que em seu artigo 198 refere-se ao Sistema Único de Saúde (SUS).

Para viabilizar as reformas necessárias para implantação do SUS, a questão da organização dos recursos humanos foi apontada como um dos principais problemas para o alcance dos objetivos a que se propunha (STEAGALL-GOMES, 1991).

Nas décadas de 70 e 80 é possível identificar alguns fatos que firmam a profissão no cenário nacional. Destacamos, entre outros, os seguintes: a aprovação da Lei $7498 / 86^{\star \star \star \star \star \star \star \star}$ que regulamentou o exercício da enfermagem; o crescimento do número de Escolas de Enfermagem e de cursos para formação de profissional técnico e auxiliar; o aumento da demanda de candidatos do sexo masculino para

\footnotetext{
****** BRASIL - Ministério da Previdência e Assistência Social. Reorientação da assistência à saúde no âmbito da Previdência Social. Brasília, Coordenadoria de Comunicação Social do MPAS. 1982. p. 42

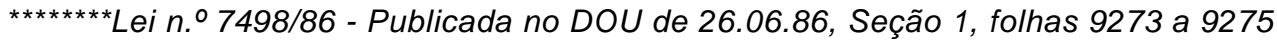


os cursos de enfermagem; a entrada formal dos enfermeiros na carreira universitária; a criação dos cursos de pós-graduação senso strictu (mestrado e doutorado) acelerando a produção do conhecimento na área da enfermagem.

ANGERAMI (1993) descreve este período como sendo o da participação da comunidade de enfermagem, para alcançar com mérito o status desejado, constituindose a pesquisa como elemento fundamental nesse processo.

Estudos realizados para avaliara produção do conhecimento em enfermagem (OPAS, 1994) mostraram que as pesquisas privilegiam indivíduos e assistência hospitalar, com diminuta produção na área da saúde pública.

Em relação ao tema assistência no domicílio, objeto deste trabalho, verificou-se que os estudos são incipientes, fato anotado por STEEL (1994) em recente pronunciamento onde também enfatizou que as mudanças demográficas que ocorrem em âmbito mundial estimulam a expansão do atendimento domiciliário. Portanto, é necessário que se desenvolvam bases educativas para essa assistência além de se organizarem grupos de pesquisa nos serviços de saúde que ofereçam o suporte necessário para esta prática.

\section{$4^{\circ}$ PERÍODO: Enfermagem no domicílio: uma tendência para o futuro?}

O Brasil chega à década de 90 num quadro de saúde cuja transição epidemiológica e demográfica é caracterizada por um aumento de casos de algumas doenças transmissíveis, ressurgimento de outras (dengue, febre amarela e cólera), altas taxas de doenças crônico-degenerativas e manutenção das carências nutricionais infantis e de adultos. Apresenta ainda, altos índices de mortalidade e morbidade por causas externas, tais como acidentes de trânsito, do trabalho e homicídios, e outras causas decorrentes da violência urbana (LAURENTI, 1990).

A prática sanitária do país passa por uma redefinição, considerando que o modelo existente já não respondia à demanda da população. Esse movimento tem seu ponto culminante com a implantação do Sistema Único de Saúde (SUS) e a municipalização dos serviços de saúde.

Em que pesem as limitações ainda presentes no processo de municipalização, essa representa um avanço sensível na organização de serviço, uma vez que a descentralização trouxe para o nível local o planejamento e a tomada de decisões, estando assim mais próxima da população.

Como resultado desta descentralização, ocorre uma mudança no quadro de prestação de serviços resultando um aumento numérico de estabelecimentos, possibilitando um maior acesso aos serviços públicos de saúde pela população (TANAKA et al., 1991).

Decorrente do incremento da capacidade instalada na rede ambulatorial tem se tornado imperativa a abertura de novos postos de trabalho, em todos os níveis, para atender a demanda crescente. Contudo, a formação dos profissionais, 
especialmente enfermeiros e auxiliares, para trabalharem neste novo modelo de assistência, tem sido criticada como desvinculada da realidade, desarticulada dos serviços e fragmentada em seus conteúdos (ANGERAMI et al., 1994).

As restrições ao currículo vigente resultaram em uma nova proposta de currículo, (Portaria, 172 1/94 $4^{\star \star \star \star \star \star \star \star \star)}$ ) que, entre outras inovações, traz o aumento da duração mínima do curso, supressão das Habilitações, proposta de formação generalista, prática em ambulatórios/rede básica, hospitais e comunidade. Observa-se que há o retorno da ênfase no ensino e prática de disciplinas de saúde pública, destacando-se a assistência na e para a comunidade, havendo uma crítica pertinente em relação ao currículo anterior por excessiva centralização no paciente hospitalizado (BRASIL, 1994).

Nos hospitais está cada vez mais explícita a política de diminuição do tempo de internação e a proposta de tratamento e seguimento dos pacientes no domicílio. 0 envolvimento do grupo familiar para esta assistência toma-se agora um problema concreto.

AGUILLAR (1990) realizou um estudo mostrando a interface entre o hospital e o domicílio, relatando as dificuldades enfrentadas pelo doente e sua família após a alta hospitalar por não saberem lidar com o doente e a doença e não receberem das instituições o apoio necessário para tal.

Reconhecendo o hiato entre o hospital e o domicílio, serviços estão sendo organizados, tanto na rede privada como pública, constituindo-se em um espaço importante de atuação para o enfermeiro.

Como exemplos de avanços na organização de serviços no domicílio citamos o Programa de Internação Domiciliar (PID) da Secretaria Municipal da Saúde de Santos ${ }^{\star \star \star \star \star \star \star \star \star \star}$, criado em 1992 e inspirado no modelo canadense que, segundo seus coordenadores, tem apresentado resultados surpreendentes.

Os autores, para ilustrar as relações que se estabelecem entre a formação e a prática profissional para a assistência no domicílio nesta década, visitaram dois serviços que prestam assistência no domicílio (um particular e outro governamental) e entrevistaram as enfermeiras responsáveis.

Optou-se por descrever o serviço na sua totalidade, para que os diferentes aspectos desta prática sejam observados.

\section{- Assistência domiciliar em clínica privada}

A clínica existe há 10 anos, embora só recentemente tenha conseguido uma visibilidade maior no âmbito da prestação de serviços. É amparada pela Lei 6839

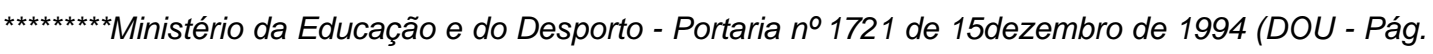
19801/02)

$\star \star \star \star \star \star \star \star \star \star$ Secretaria de Higiene e Saúde - Programa de internação domiciliar - A melhor casa de saúde é a sua - Prefeitura Municipal de Santos - 1994.
} 
de $1980^{\star \star \star \star \star \star \star \star \star \star \star}$ que permite aos enfermeiros este tipo de trabalho. Sendo uma empresa particular, as ações realizadas são pagas pelo cliente, portanto é um serviço preferencialmente prestado às classes mais abastadas.

A motivação para o pioneirismo neste tipo de trabalho em Ribeirão Preto, segundo a entrevistada, partiu da observação, ainda quando estudante, de que o cliente, ao sair do hospital, continuava dependente da enfermagem.

Do estilo inicial de atendimento no domicílio, quando solicitado, hoje a clínica mantém, além do cuidado domiciliário, um serviço de internação para pacientes.

A clientela atendida apresenta as seguintes características: idosos com paralisias, problemas neurológicos, fraturas ou pós-cirúrgicos, os quais permanecem internados de 3 dias a 1 mês, dependendo do processo de reabilitação.

Para este atendimento conta com uma equipe formada por enfermeiros, fisioterapeutas, auxiliares de enfermagem e atendentes. O médico é chamado sempre que necessário.

No ambulatório, atende pacientes que solicitam cuidados específicos tais como: curativo, injeções, havendo uma crescente procura para hidratação endovenosa, orientação a diabéticos, ostomizados e outros.

O avanço tecnológico permitiu o desempenho das ações de enfermagem utilizando material e aparelhagem disponíveis no mercado. Os serviços de apoio (lavanderia, esterilização e alimentação dos clientes) são gerenciados e executados na própria clínica.

O cuidado no domicílio, atividade exercida desde a origem, tem características de acompanhamento de 24 horas, em rodízio de plantão ou por horas, dependendo da necessidade do cliente. Esta assistência é administrada por enfermeiros e executada por pessoal auxiliar.

A entrevistada relata a permanência da característica histórica do cuidado domiciliário, fato de na clínica ainda serem procuradas pessoas que atendam ao doente e executem os afazeres domésticos, sendo ainda necessário orientar a clientela quanto ao significado do cuidado de enfermagem.

Além da dificuldade descrita, qual seja da população não entender a diferença entre o cuidado de enfermagem e trabalho doméstico, outra dificuldade reside nos recursos humanos disponíveis e seu preparo.

Para ela, as escolas de nível técnico e superior não enfocam o cuidado no domicílio, centralizando o ensino no atendimento hospitalar.

Assim, o enfermeiro apresenta limitada capacidade de decidir com independência e atuar longe do médico. O trabalho autônomo é desejado pelo enfermeiro, mas ao se defrontar com distintas situações, este sente-se limitado em

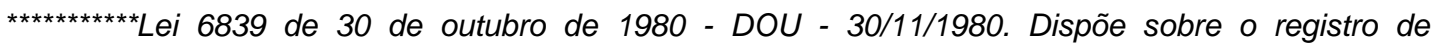
empresas nas entidades fiscalizadoras do exercício da profissão. 
suas competências e habilidades, devido à preponderante formação hospitalar. Frente à situação descrita, sugere que as Escolas de Enfermagem desenvolvam em seus alunos, a liderança, habilidade em gerenciamento de serviços, conhecimento da legislação e responsabilidade profissional para o desempenho das novas funções exigidas na assistência domiciliar.

A perspectiva da entrevistada é a de que haverá ampliação de serviços com estas características, devida à crescente procura, às transformações dos hospitais, ao elevado custo da hospitalização e ao crescimento da população idosa, constituindo-se uma área em expansão no mercado de trabalho para a enfermeira.

\section{- Assistência domiciliária de caráter público}

Na rede pública, o serviço de assistência no domicílio também se faz presente. Um projeto do Ministério da Saúde tem sido um estímulo para sua implantação em algumas cidades.

A incipiente produção científica nesta área tem levado as profissionais a difundirem suas experiências em reuniões técnicas, grupos de planejamento e outros (KEMURA \& TOCIO, 1994).

Para conhecer o que ocorre num serviço de atendimento domiciliário público, foi entrevistada a enfermeira responsável pelo projeto de Serviço de Assistência Domiciliar de Ribeirão Preto do município de Ribeirão Preto, acompanhando os mesmos itens inquiridos para a enfermeira do serviço particular.

O projeto teve início em julho de 1993 (PEREIRA, 1994). Com o objetivo de promover assistência integral ao paciente através da visita domiciliária realizada por uma equipe da Unidade Básica de Saúde. As pessoas a serem incluídas como caso índice devem ter registro e seguimento médico na Unidade Básica de Saúde e ter algum membro da família ou vizinho como apoio para o desempenho dos cuidados necessários.

A população alvo é constituída por pacientes: faltosos, crônicos, com seqüelas de A.V.C., necessitando de curativos e orientações e outros casos quando há solicitação.

A partir do pedido de Visita Domiciliária, há uma reunião da equipe para avaliar os recursos humanos a serem indicados para solução do problema: fisioterapeuta, enfermeiro, médico, auxiliar de enfermagem ou outro.

A visita é considerada um momento privilegiado para interação do serviço de saúde com a família. Assim, não é atendido apenas o cliente e seu problema, mas são discutidas com a família as questões ambientais e suas relações com saúde física e mental. Como exemplo, cita que, em algumas casas, são detectados problemas de saúde mental em que há riscos de violência com menores. Isto leva a estabelecer um trabalho com a tutela de menores, até a solução do problema. As relações podem se estabelecer também com o serviço de saneamento básico, 
Secretaria da Educação e Bem Estar Social e outras, dependendo da situação da família. Assim sendo, a freqüência e o número de visitas são determinadas pela necessidade da clientela.

A limitação de recursos humanos e materiais disponíveis tem sido fatores limitantes do programa.

Em relação aos recursos materiais, faltam transporte e equipamentos, principalmente aqueles que devem permanecer no domicílio.

Quanto aos recursos humanos, além do número reduzido para a crescente demanda, demonstram deficiências no seu preparo, deficiências essas que estão sendo sanadas pelo próprio serviço e na vivência do profissional em distintas situações.

Os enfermeiros treinados em hospital, sempre dependentes do ato médico, têm tido dificuldades no processo decisório. Os recém formados não têm tido preparo em assistência domiciliária, nos currículos não há ênfase nesta área e inexistem programas de Educação Continuada. Portanto, os próprios serviços, através de oficinas de trabalho, suprem esta lacuna, ficando patente que a responsabilidade do preparo para assistência no domicílio está sendo assumida pelos serviços, com restrita participação das Escolas de Enfermagem.

Acrescente-se a esta problemática a visão de mundo do profissional centrada na doença, no doente e na cura, dificultando a compreensão do novo enfoque na família e seu ambiente, na promoção da saúde e melhor qualidade de vida.

Quanto a esta população, assim como no serviço particular, não entende este cuidado de enfermagem e identifica o enfermeiro como um assistente social.

O programa descrito está sendo desenvolvido em apenas seis (6) Unidades Básicas de Saúde, das 30 existentes no município. Há, entretanto, previsão da continuidade do serviço além da ampliação do atendimento.

\section{CONSIDERAÇÕES FINAIS}

O percurso descrito através dos quatro períodos da história, analisando a formação profissional do enfermeiro para a assistência no domicílio e as mudanças no setor saúde e educacional, permite tecer algumas considerações.

Para entender se existe uma tendência para a assistência domiciliar e mudança de paradigma assistencial, foi utilizado o conceito de tendência de ABURDENE \& NAISBITT (1993) que é: A mudança social acontece quando há massa crítica (...) A massa crítica é como um desmoronamento da terra; é quando uma tendência se transforma em uma megatendência; é o ponto em que um paradigma social aceito não tem mais sentido e é substituído por outro. Os mesmos 
autores dizem ainda: Estaremos substituindo nosso paradigma de assistência? ROGERS (1993) acrescenta quando 13\% de uma população aceita uma idéia nova é só uma questão de tempo até que pelo menos $84 \%$ incorporem a idéia. O tempo atua como um fator desconhecido.

Através dos exemplos apresentados, é possível dizer que os problemas de saúde vivenciados pela população têm estimulado a busca por soluções distintas daquelas tradicionalmente oferecidas. A assistência no domicílio vem constituindo uma estratégia frente às crescentes pressões para melhoria da qualidade e quantidade da assistência em saúde.

Em ambos os programas descritos, o idoso apresentou-se como o grupo de maior demanda, o que pode ser explicado pela transição demográfica e epidemiológica. ABURDENE \& NAISBITT (1993) dizem a população idosa e a necessidade de reduzir custos da assistência à saúde estão provocando expansão na assistência domiciliar à saúde.

Para uma cidade com um alto grau de desenvolvimento político-socialeconômico, onde estão localizados os dois serviços descritos, ainda não é permitido dizer que há uma tendência para a assistência domiciliária, segundo o padrão dos autores citados, contudo, é possível afirmar que tem havido um crescimento desses serviços, especialmente na última década, tanto no setor privado como público.

A trajetória histórica, semelhante à percorrida por KIRKIS (1993), permitiunos chegar a conclusões similares: o cuidado domiciliário retornou ao lugar ocupado no passado no sentido de cuidar dos doentes em suas casas e à ênfase no ensino dos princípios higiênicos. Portanto, o preparo de enfermeiros que desenvolvam esta prática com competência e habilidade, na realidade que se está apresentando, é um desafio para todas as Escolas de Enfermagem de nível superior e/ou técnica. Presume-se que, além da prestação de cuidados domiciliares, inicia-se a formação de uma nova equipe de trabalho que terá como desafio maior lidar com pessoas na sua família, exigindo um profundo conhecimento e habilidades nas relações humanas além do preparo ético para decidir nas distintas situações que se apresentarem.

Os programas educacionais e os serviços de saúde devem mobilizar-se nesta direção. Nas Escolas de Enfermagem, a ênfase no preparo para esta atividade ainda se mostra restrita e o currículo a ser implantado não particulariza esta área de assistência. Estas observações também foram assinaladas nas entrevistas realizadas com as enfermeiras dos serviços visitados, quando abordaram a questão dos recursos humanos.

A trajetória descrita permite dizer também que está ocorrendo uma transformação no paradigma em saúde e que o espaço da enfermeira de saúde pública se amplia e a assistência no domicílio emerge como proposta para qualidade dos serviços em saúde.

Este novo momento, que pode ser entendido como um retorno a uma prática que já foi predominante, apresenta-se com novas características de vidas aos 
avanços técnicos e científicos e à importância que vem sendo atribuída à participação da família e do cliente no cuidado à saúde em seus aspectos de promoção, prevenção e cura.

Cabe ainda ressaltar que os serviços de saúde devem considerar saúde um direito das pessoas, que merecem serviços justos, que atendam suas necessidades, respeitando sua dignidade e que propiciem melhor qualidade de vida.

\section{AN ANALYSIS OF HOW NURSES ARE PREPARED FOR HOME CARE}

The authors observed that there is a tendency towards looking after the sick at home. Therefore they have carried-out this analysis of how nurses are prepared for home care. There are four historical periods with important bearings that have directly or indirectly influenced Brazilian nursing profession and education since 1923, the authors searched within the basic curriculum. To find references about home care in the courses oriented to public health. The analysis confirms a tendency in this area, both in public and private health services. However Nursing Schools are not considering yet these areas that will be really important in the near future.

UNITERMOS: home care nursing, formation, curriculum

\section{ANÁLISIS DE LA FORMACIÓN DEL ENFERMERO PARA LA ASISTENCIA DE ENFERMERÍA EN EL DOMICILIO}

La observación de que hay un regreso a la asistencia domiciliaria, llevó a los autores a realizar este estudio, con el objetivo de analizar la formación del enfermero para ese cuidado. Fueron demarcados cuatro periodos históricos en los cuales están identificados algunos hechos que directa o indirectamente influenciaron en la enfermería Brasileña y la formación de profesionales. Los autores buscaron en los currículos mínimos fijados a partir de 1923, las disciplinas de salud pública y en ellas los contenidos que favorecen la formación para la práctica de esa asistencia. La descripción de los dos servicios (público y privado) que utilizan esa asistencia, ayuda a la discusión de que efectivamente hay una tendencia para ese tipo de cuidado y que la formación del enfermero tradicionalmente no contempló ni contempla esa preparación, constituyéndose frente a la realidad y a la expansión del mercado, en una área relevante.

TÉRMINOS CLAVES: enfermería en el domicilio, formación, currículo 


\section{REFERÊNCIAS BIBLIOGRÁFICAS}

01. ABURDENE, P.; NAISBITT, J. Megatendência para as mulheres. Trad. Magda Lopes. Rio de Janeiro: Rosa dos Tempos, 1993.

02. AGUILLAR, O.M. A alta do paciente cirúrgico no contexto hospitalar. Ribeirão Preto, 1990. 104p. Tese (Doutorado) - Escola de Enfermagem de Ribeirão Preto, Universidade de São Paulo.

03. ALCÂNTARA, G. A enfermagem moderna como categoria profissional: obstáculos à sua expansão na sociedade brasileira. Ribeirão Preto, 1963. 125p. Tese (cátedra de História e Ética) - Escola de Enfermagem de Ribeirão Preto, Universidade de São Paulo.

04. ALMA - ATA. Cuidados primários de saúde - 1978. CONFERÊNCIA INTERNACIONAL SOBRE CUIDADOS PRIMÁRIOS DE SAÚDE, Relatório. ALMA - ATA, URSS, 6 - 12 set. 1978. Brasil: Unicef. 1979.

05. ANGERAMI, E.L.S. O mister da investigação do enfermeiro. Rev. Latino-Am. Enfermagem, v. 1, n. 1, p. 11-22, jan. 1993.

06. ANGERAMI, E.L.S. et al. Estudo comparativo na nomenclatura das matérias e disciplinas do currículo mínimo, com a utilizada pelas Escolas de Enfermagem da região Sudeste - Brasil, 1994. 17p. / Mimeografado/

07. BAER, E. Nursing's divided house - an historical view. Nurs. Res., v.35, n. 1, p.32-8, 1984.

08. BARREIRA E CASTRO, I. Aspectos críticos do desempenho de funções próprias da enfermagem na assistência ao paciente não hospitalizado. Rio de Janeiro, 1977. 93p. Dissertação (Mestrado) - Escola de Enfermagem Ana Neri, Universidade Federal do Rio de Janeiro.

09. BEATRICE, J; KALISCH, P. Slaves, servants, or saints? Nurs. Forum, v. 14, n. 3, p. 223-63, 1975.

10. BRAGA, J.C.S. A questão da saúde no Brasil: um estudo das políticas sociais em saúde pública e medicina previdenciária no desenvolvimento capitalista. Campinas, 1978. 209p. Dissertação (Mestrado) - Departamento de Economia e Planejamento Econômico, UNICAMP.

11. BRASIL. Ministério da Educação e Cultura. Conselho Federal de Educação. Currículo mínimo para o Curso de Enfermagem. Parecer 314/94. Brasília, abr. 1994. 17p. /Mimeografado/

12. CARVALHO, A. Escola de Enfermagem da Universidade de São Paulo: Resumo histórico - 1942-1980. São Paulo, 1980.

13. CARVALHO, A.C. Orientação e ensino de estudantes de enfermagem no campo clínico. São Paulo, 1972. 150p. Tese (Doutorado) - Escola de Enfermagem, Universidade de São Paulo. 
14. CONSELHO FEDERAL DE ENFERMAGEM. Associação Brasileira de Enfermagem. O exercício da enfermagem nas instituições de saúde do Brasil. 1982/1983: força de trabalho em enfermagem. Rio de Janeiro. COFEN/ABEn, 1985. v.1, 236p.

15. GOLDMARK, J. Nursing and nursing educations in the United States. Report of Committee for the nursing and nursing education. N.L.N.E., 1993.

16. HEALTH CENTER ADVISORY CENTER. The emergency of hospital nursing. Health/PAC Bulletin, n. 65, 1975.

17. KEMURA, M.L.R.; TOCIO, M.O. SEMINÁRIO NACIONAL DE ASSISTÊNCIA DOMICILIAR. Relatório. São Paulo: Santos, 21 a 27/set 1994. /Mimeografado/

18. KIRKIS, J. Home health/public. Health/visiting nurse returning to our past. Home health care nurse, v. 11, n. 5 p. 9-13, 1993.

19. LAURENTI, R. Transição demográfica e transição epidemiológica. In: CONGRESSO DE EPIDEMLOLOGIA, 1, Campinas. Anais. Campinas, 1990. p. 143-65.

20. MINZONI, M. A.; SAPORITI, E. L.; MARTELLI, Z. B. Experiência de um curso de enfermagem no lar numa pequena comunidade. Rev. Bras. Enfermagem, v. 16, n. 4, p. 292-9, ago. 1963.

21. OLIVEIRA, M. I. R. Enfermagem e estrutura social. In: CONGRESSO BRASILEIRO DE ENFERMAGEM, 31, Fortaleza. Anais. Brasília: ABEn, 1979. p. 9-26.

22. OPAS. Estudio de las tendencias de investigação sobre la práctica de enfermería en siete Países de la América Latina. Washington, DC, 1994. (Resumo Final).

23. PARSON, E. Modern nursing in Brazil - Am. J. Nurs., v. 27, n. 6, p. 443-9, 1927.

24. PEREIRA, M. J. B. Projeto de serviço de assistência domiciliar. Ribeirão Preto: Secretaria Municipal da Saúde, 1994. 18 p. /Mimeografado/

25. PULLEN, B .L. Our south american collegues. Am. J. Nurs., v. 40, n. 2, p. 153-7, 1940.

26. REZENDE, M. A. Ensino de enfermagem. Rev. Bras. Enfermagem, v. 14, n. 2, p. 110-58, 1961.

27. SILVA, G. B. A enfermagem profissional brasileira: análise crítica. São Paulo: Cortez, 1986. $143 \mathrm{p}$.

28. STANDARD CURRICULUM FOR NURSING SCHOOLS. In: BIXLER, R. N.; BIXLER, G. K. Administration for nursing education, New York: G.P. Putman's Sons, 1954.

29. STEAGALL-GOMES, D. L. Estudo sobre atendentes e visitadores sanitários na força de trabalho de enfermagem de saúde pública ERSA 50. Ribeirão Preto, 1991. 163 p. Tese (Livre docência) - Escola de Enfermagem de Ribeirão Preto, Universidade de São Paulo. 
30. STELL, K. Home Care: a view of montaine. In: Opening the doors to home care nursing. Proceeding book. Pádua, Itália, 1995. p. 45.

31. TANAKA, O. Y. et al. A municipalização dos serviços de saúde no Estado de São Paulo. Saúde e Debate, n. 33, p. 713-9, 1991.

32. WAGNER, D. The proletarization of Nursing in the States, 1932- 1946. Int. J. Health Services, v. 10, n. 2, p. 271-90, 1980. 